ORIGINAL ARTICLE

\title{
The potential impact on costs and staffing of introducing clinical networks and British Association of Perinatal Medicine standards to the delivery of neonatal care
}

\author{
E S Draper, B N Manktelow, C McCabe, D J Field
}

Arch Dis Child Fetal Neonatal Ed 2004;89:F236-F240. doi: 10.1136/adc.2003.034512

See end of article for authors' affiliations

Correspondence to

Correspondence to:
Dr Draper, Department of Health Sciences, University of Leicester, 22-28 Princess Road West, Leicester LE1 6TP, UKK msn@leicester.ac.uk

Accepted 6 August 2003

\begin{abstract}
Objective: To produce models to estimate the impact of introducing clinical networks and the 2001 BAPM standards to the delivery of neonatal care.

Design: Prospective observational study using a geographically defined population and data collected by questionnaire on staffing levels and cot availability.

Setting: Trent Health Region UK.

Subjects: All infants born to Trent resident mothers at or before 32 weeks gestation between 1 January 1998 and 31 December 1999. Staffing numbers and cot availability for neonatal care in 2001.

Methods: A modelling exercise was carried out using information for all neonatal admissions for Trent resident infants. Three models were investigated: $(a)$ the current care provision; (b) a network where three lead centres provided the intensive care for the region and the remaining units provided either high dependency or special care alone; $(c)$ a network where six lead centres provided the intensive care for the region and the remaining units provided either high dependency or special care alone. Overall costings, staffing levels, and cot requirements were calculated for each model. Data on staffing levels and cot availability were used to calculate current care provision costings.

Results: The current cost of running the service is approximately $£ 33.35$ million, although a proportion of nursing posts are currently unfilled. Estimates for the introduction of a three centre model meeting BAPM 2001 standards range from $£ 37.31$ to $£ 43.40$ million. Equivalent figures for the six centre model were: $£ 36.32$ to $£ 42.62$ million. Approximately 370 and 230 babies a year would be involved in transfer in the three and six centre models respectively. This is in contrast with 374 and 368 urgent transfers that actually took place in 1998 and 1999 respectively.

Conclusion: The costs associated with the introduction of managed clinical networks and meeting BAPM standards of care are not excessive, especially when considered against the likely implementation timetable of perhaps 7-10 years. Attracting and retaining sufficient staff will pose the major challenge.
\end{abstract}

It was proposed that each clinical network would comprise at least one intensive care unit providing the full range of neonatal care to infants of any gestation, high dependency units providing care to a more limited group of infants-for example, infants requiring level 1 intensive care for between one and two days only-and special care units providing no long term intensive care apart from the stabilisation of infants after birth. The units would work cooperatively in all clinical matters to optimise the care of babies born to mothers living in the catchment area of the network of perhaps 12000 to 25000 births. One full intensive care unit in each network would take on a wider organisational and educational role and be designated a lead centre.

The potential impact of these radical changes on the NIC service was largely unknown in terms of even the most basic issues such as the number of transfers that would be required under the new arrangements. Similarly, costs were hard to estimate with any certainty. The situation was further complicated by the fact that the BAPM 2001 standards document ${ }^{3}$ recommended an increase in both medical and nurse staffing to ensure the optimal care of high risk infants.

The Trent Neonatal Survey team attempted to address these issues by embarking on a modelling exercise to estimate the impact of trying to $(a)$ introduce clinical networks and $(b)$ meet the new BAPM standards over the next few years within the Trent region. Help with this

Abbreviations: BAPM, British Association of Perinatal Medicine; NIC, neonatal intensive care concurred with this view and used such networks in the national plan for NIC services. ${ }^{4}$ 
exercise was sought from many clinical staff across the region and a health economist.

\section{METHODS}

The Trent Neonatal Survey is a continuing, population based study of neonatal intensive care activity in the former Trent Health Region. The region has a population of approximately 4.6 million and just over 55000 births per annum. All 18 perinatal services contribute to the study. Units adjacent to the region also permit data collection on Trent infants. The survey was established in February 1990. Data are collected for the survey by five part time research nurses who visit each of the neonatal units on a regular basis.

The modelling exercise was based on survey data from 1998 and 1999. Although the survey provides information about the overall levels and location of intensive care activity for the region, it does not collect information about special care, and therefore assumptions about the amount of special care provided by each unit were made in the modelling process-that is, that it remained unchanged after the introduction of networks. Additional information about the existing numbers of cots and staffing levels (in 2001) on each unit were collected using a questionnaire, adapted from the UK neonatal staffing study, sent to the senior nurse on each unit. $^{5}$

After regional discussions, two proposals for the potential reorganisation of NIC provision within the Trent health region were considered and compared with the current situation:

- Three networks: with one intensive care/lead unit per network and with the remaining units providing either high dependency and special care (nine units) or special care alone (two units).

- Six networks with one intensive care/lead unit per network and with the remaining units providing either high dependency and special care (six units) or special care alone (two units).

Figure 1 presents the geography of these models.

It was assumed that both network models would operate with a fully staffed transport team in place operating across the whole region, in keeping with current recommendations. The scenarios chosen were by no means the exclusive possibilities available and were chosen simply to illustrate the impact of introducing clinical networks and the new BAPM standards to current neonatal practice.

The cost of imposing BAPM 2001 standards for clinical nursing staff requirements was calculated for each model using the standard formulae prescribed ${ }^{3}$ and the activity data for the region over the two years studied. The gradings of clinical nursing staff were allocated in the same proportions as the current establishment. All models for nurse staffing were produced for occupancy levels of $70-90 \%$, with an $80 \%$ occupancy being assumed for all special care cots. Average occupancy was derived from a simple arithmetical distribution of the annual workload of each unit. Values for nursing salaries were derived from 2001-2 NHS scales using the midpoint of the relevant scale and assuming a $17.5 \%$ overhead for employment costs.

The BAPM 2001 standard specifies clear requirements for medical cover including a separate middle grade staff rota and dedicated consultant cover for lead centres. In this exercise, this was defined as: seven whole time equivalents of each of senior house officers (SHOs), specialist registrars (SpRs), and consultants for the lead centres and other intensive care units, seven whole time equivalent SHOs with seven half time equivalent SpRs and consultants for the high dependency units, and seven half time equivalent SHOs and SpRs and seven quarter time equivalent consultants for the special care units. Given the large range of medical salary scales, cost estimates were derived using three separate sets of assumptions:

- All staff at the bottom of the relevant scale

- All staff at the midpoint on the scale

- All staff on the top of the scale

Because of the large throughput of the lead centres in the three centre model, an extra 50\% medical staffing level was applied, and a sensitivity analysis was carried out around the midpoint of the scale estimate.

The staff for the transport team was assumed to be: one consultant (in charge); seven SpRs and seven nurses (three F grades, two $\mathrm{G}$ grades, and two $\mathrm{H}$ grades).

Analysis and modelling of the Trent Neonatal Survey data were carried out using the following assumptions:

- No units closed

- Full intensive care unit provision would be in three designated units in the three centre model and six
3 Centres

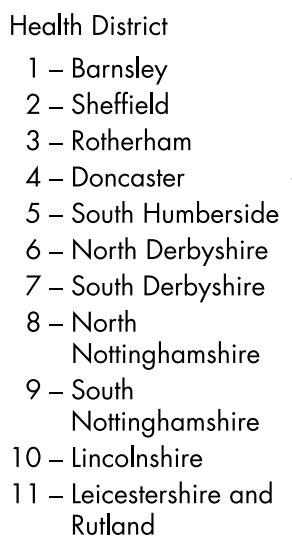

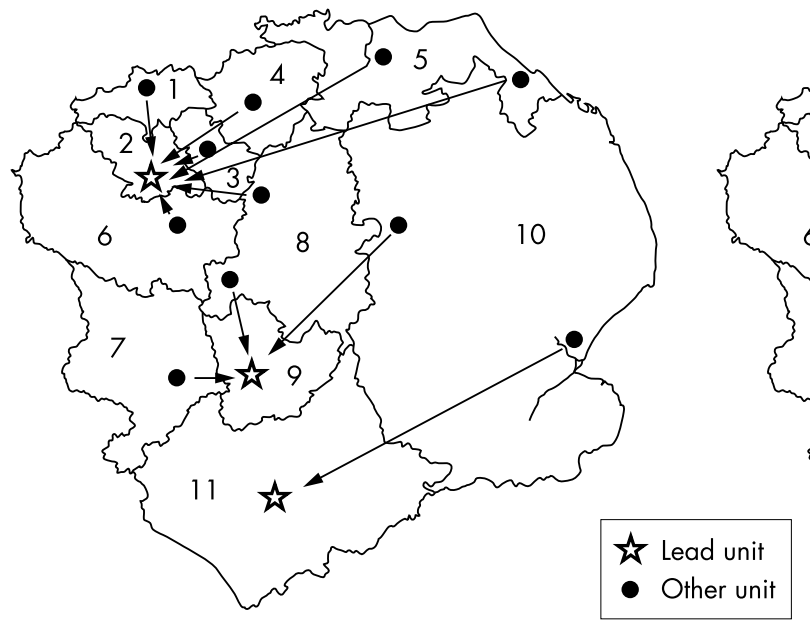

Figure 1 Maps showing the networks for the three and six centre models of neonatal care. 
designated units in the six centre model—that is, one per network

- All units would require the equivalent of one intensive care cot

- High dependency units would provide level 1 care for up to 24 hours while the need for long term level 1 care was assessed-that is, during modelling, babies who needed $\leqslant 24$ hours intensive care were assumed not to need transfer from a high dependency unit

- High dependency units would provide level 2 intensive care and special care

- Infants born in a special care unit requiring high dependency or intensive care would be transferred to a defined intensive care unit

- Infants born in intensive care units would remain there for all their care unless requiring transfer to a specialist unitfor example, for extracorporeal membrane oxygenation.

The definitions of intensive care and high dependency care were based, as closely as existing data allowed, on the most recent BAPM definitions. ${ }^{3}$

The area covered by each managed clinical network, with the related transfer pattern, was agreed by the local clinicians.

The modelling was carried out using SAS v8.1, and the associated costings were calculated using an Excel 2000 spreadsheet.

\section{RESULTS}

The current costs for neonatal care within the Trent region are $£ 5.939$ million for medical staff, $£ 10.811$ million establishment costs for nursing staff (although staff equivalent to only $£ 9.064$ million are currently in post), and an estimated $£ 16.275$ million of capital equipment costs. Staffing costs for transport are included within the overall cost as there is currently no separately funded transport team. The total current costs were therefore $£ 33.532$ million per annum.

Table 1 provides the estimated cost of clinical nursing staff for neonatal care in the former Trent region using the three and six network models. BAPM 2001 standards have been applied to the calculations. The estimated costs for these staff in the three lead centre model, over an average bed occupancy of $70-90 \%$, ranges from $£ 13.242$ million to $£ 11.826$ million per annum. The estimated costings for the six lead centre model range from $£ 12.826$ million to $£ 11.409$ million per annum.

Table 2 presents the estimated annual costs for medical staff, indicating lower, midpoint, and upper salary scale estimates. Overall the costs are very similar for the two models: $£ 11.102$ million for the three lead centre model and $£ 10.789$ million for the six lead centre model. In the three lead centre model, we present a central estimate assuming a $50 \%$ medical staffing premium, with a sensitivity analysis

\begin{tabular}{|c|c|c|}
\hline \multirow{2}{*}{$\begin{array}{l}\text { Average bed } \\
\text { occupancy }\end{array}$} & \multicolumn{2}{|l|}{ Costs in $£$ millions } \\
\hline & Three lead centres & Six lead centres \\
\hline $70 \%$ & 13.242 & 12.826 \\
\hline $75 \%$ & 12.940 & 12.525 \\
\hline $80 \%$ & 12.414 & 11.999 \\
\hline $85 \%$ & 12.236 & 11.941 \\
\hline $90 \%$ & 11.826 & 11.409 \\
\hline
\end{tabular}

Table 2 Estimated annual costs of medical staff for the two models, Trent region: BAPM 2001 standards

\begin{tabular}{lcc}
\hline \multicolumn{3}{c}{ Costs in $£$ millions } \\
\cline { 2 - 3 } & Three lead centres & Six lead centres \\
\hline Lower estimate & 8.704 & 8.428 \\
Midpoint estimate & 11.102 & 10.789 \\
Upper estimate & 13.382 & 13.014 \\
Sensitivity analysis & 9.534 to 12.671 & \\
for three lead centre & & \\
model & & \\
\hline & \\
Estimates are based on staff working on the bottom, middle, \\
or top of the pay scale. The sensitivity analysis for the three \\
lead centre model is based on the midpoint estimate.
\end{tabular}

assuming a staffing premium range of $0-100 \%$ : $£ 9.534$ to £12.671 million.

The estimated cost of the dedicated transport team for both models is just over half a million pounds ( $£ 0.507$ million), with medical and nursing salaries assumed to be the midpoint of the scale.

The overall costings for the three lead centre model including transport and assuming the same level of capital costs are estimated to be within the range $£ 37.312$ million to $£ 43.406$ million per annum for the region. This compares with the range $£ 36.319$ million to $£ 42.622$ million for the six lead centre model.

Tables 3 and 4 present the estimated whole time equivalent numbers of clinical nursing and medical staff required for the two models. Once again the nursing figures (table 3) are given for a range of average bed occupancies from $70 \%$ to $90 \%$. Across the range of bed occupancies, there is a constant increased requirement for nursing staff of about 20 whole time equivalents in the three compared with the six lead centre model: 647.9-578.9 compared with 627.8-558.8 whole time equivalent nursing staff.

The actual establishment figure for nursing staff in 2001 for the region was 529.5 whole time equivalents, of which only 453.3 (85.6\%) were filled.

The only difference in the estimated numbers of whole time equivalent medical staff required by the models of care is for SHOs, where 101.5 are required for the three lead centre model whereas only 91 are required in the six lead centre model. In 2001, actual numbers of medical staff were as follows: 34 consultants, 35 SpRs, and 62 SHOs.

The overall effect of managed clinical networks on the number of infants transferred is hard to estimate accurately as some transfers, such as those for a specialist investigation, will not be affected. However, using the rules described above, about 370 babies a year would be transferred for intensive care in a three centre model and 230 a year in a six

Table 3 Estimated whole time equivalent (wte) numbers of clinical nursing staff required for the two models for neonatal care with average bed occupancies of $70-90 \%$, Trent region: BAPM 2001 standards

\begin{tabular}{lll}
\hline \multirow{2}{*}{$\begin{array}{l}\text { Average bed } \\
\text { occupancy }\end{array}$} & \multicolumn{2}{l}{ Regional nursing staff requirement (wte) } \\
\cline { 2 - 3 } & Three lead centres & Six lead centres \\
\hline $70 \%$ & 647.9 & 627.8 \\
$75 \%$ & 633.5 & 613.4 \\
$80 \%$ & 607.6 & 587.5 \\
$85 \%$ & 599.0 & 584.6 \\
$90 \%$ & 578.9 & 558.8 \\
\hline
\end{tabular}


Table 4 Estimated whole time equivalent (wte) numbers of medical staff required for the two models for neonatal care, Trent region: BAPM 2001 standards

\begin{tabular}{lcl}
\hline & \multicolumn{2}{c}{ Regional medical staff requirement (wte) } \\
\cline { 2 - 3 } & $\begin{array}{l}\text { Three lead centres } \mathbf{5 0 \%} \\
\text { additional staff for lead } \\
\text { centres) }\end{array}$ & Six lead centres \\
\hline Consultants & 66.5 & 66.5 \\
SpRs & 70.0 & 70.0 \\
SHOs & 101.5 & 91.0 \\
\hline
\end{tabular}

$\mathrm{SpR}$, Specialist registrar; SHO, senior house officer.

centre model. This is in contrast with the 374 and 368 in utero and urgent postnatal transfers that actually took place in 1998 and 1999 respectively. Some of the transfers in 1998 and 1999 were out of regional centres.

\section{DISCUSSION}

The current service for neonatal intensive care is dysfunctional. At present it is nurse staffing that is the major problem, but changes in medical staff training and the European Working Time Directive will add new challenges. The introduction of managed clinical networks is seen as the best way to deal with all of these issues. However, the development of managed clinical networks and the introduction of new standards for both medical and nurse staffing have major implications for the service. The models of care presented in this study produced very similar results, both resulting in a significant increase in both the funding and staff requirements. The average level of occupancy for a unit is a compromise between the maximum cost effectiveness and the amount of pressure managers are willing to exert on their staff. In addition, to maintain an efficient network, the units will need to have some flexibility, thus the cheaper $90 \%$ occupancy level may not be appropriate. The overall costs of neonatal care from the models differed by an average of only $£ 0.75$ million per annum. Nevertheless, the overall required funding increase, over and above current costs, was estimated to be $11-31 \%$ for neonatal care, including all staffing costs, a dedicated transport team, and assuming no increase in the capital cost expenditure: a sum of between $£ 3.1$ and £9.9 million per annum. Total medical staffing costs are by far the largest contributor to this increase, with a doubling of the requirement for consultant and SpR staff and an increase of about $50 \%$ in the SHO requirement. Much of this increase is due to the effect of planning to meet the European Working Directive on doctors' hours, a point that is incorporated into the BAPM 2001 standards. ${ }^{3}$ The increase in the cost of nursing staff in the models compared with current establishment costs is much less: 5.5-22.5\%. However, staffing shortages are such that current establishment levels are not being achieved in most units (currently 76.2 whole time equivalent unfilled nursing posts across the region), and therefore even the most modest increase, suggested in the models, of about 30 nurses is unlikely to be attained in the current climate without the introduction of other changes such as more family friendly working practices. However, it is important to remember that this exercise incorporated no reduction in staffing levels as a result of babies needing longer term intensive care being transferred. Indeed the staffing of units doing less work under these new arrangements were based on the most recent BAPM standards and hence increased.

Our ongoing data indicate that overall workload remains fairly stable, and hence the conclusions of this study, which are based on data from 1998 and 1999, remain valid. However, we recognise a growth in high dependency care in recent years, and we acknowledge that, for the networks to operate efficiently, babies must not only be able to move into intensive care units when appropriate but also be able to return to their local unit promptly when the intensive care episode has ended. Therefore it will be important that networks focus on high dependency capacity and reliable transport services and not just intensive care capacity. As a result of these concerns, it may seem that our estimate of a single transport team is inadequate. Although this may be the case at peaks of activity, we have assumed that all units are capable of providing intensive care in the short term and hence there should be no need to plan on increased transport capacity simply so that a baby can be "rescued" at very short notice. It is also important to note that the models did not incorporate a blanket policy of moving to an intensive care unit all babies below a certain gestation. This has been suggested as part of a policy of introducing networks and would clearly further affect patient flows. Indeed the recent report from CESDI has recommended the establishment of national standards for both in utero and ex utero transfers, pointing out that currently such cases are dealt with in an unacceptable ad hoc manner. ${ }^{6}$

Clearly the cost of introducing such changes across the United Kingdom would be large and can be estimated on the basis that Trent is about one tenth of the size of England and Wales. However, a "do nothing option" does not avoid the implications of the European Working Time Directive, which will potentially greatly increase cost without necessarily resolving the current problems of capacity. In addition, any change would be phased because we are not currently training sufficient people to fill the new roles. Therefore the increased cost would be spread over many years. No consideration has been given to the wider use of nurse practitioners. At an early stage in any modernisation, there would need to be an expansion of the number of training courses for these professionals who have great potential for filling some traditionally medical roles in the future. It is these rather ill defined infrastructure costs, which would need to occur early in the process of change if later elements are to be feasible, that have not been included in the models presented here.

It seems reasonable that the return on such a large investment should be compared with the return on alternative uses of those resources, such as simply increasing capacity to reduce the number of occasions when infants are exposed to care in units with high occupancies. The UK neonatal staffing study results suggest that there is a relation between risk adjusted outcome and unit occupancy during an infant's admission. ${ }^{7}$ As a result it would be important to monitor any new service closely to ensure that improvements did occur. This would include medical measures such as mortality and later health status as well as patient centred measures such as a reduction in the number of out of area transfers. These measures would require much greater harmonisation of data collection, and hence the introduction of networks should be accompanied by an appropriate IT strategy.

The development of clinical networks as proposed by the BAPM and used in the recent Department of Health review relies on the assumption that the associated major reorganisation of neonatal intensive care services will have no negative aspects in terms of quality of care. It will be important to test this assumption carefully. Although the present service is dysfunctional, and definitely not family friendly, it does appear to deliver an equal standard of care to all high risk preterm infants, irrespective of their place of delivery and care in the United Kingdom. ${ }^{78}$

Although there are risks to the introduction of networks for neonatal intensive care, they also have the potential to 
place the service on a more sound footing than ever before. The costs are not excessive when considered against the likely timescale for implementation (perhaps 7-10 years) and therefore the changes should be affordable. The organisational model has delivered major improvements for paediatric intensive care and is already providing a sound structure for adult intensive care. The challenge for neonatal intensive care is to adapt the model to deal with the particular problems confronting the service.

\section{ACKNOWLEDGEMENTS}

We would like to thank Professor Neil Marlow and Dr Sandie Bohin for their helpful input into the modelling exercise, all clinical staff working in the neonatal units across the former Trent region, and the Trent Neonatal Survey nurses. The Trent Neonatal Survey is funded from a regional levy comprising contributions from all district health authorities in Trent. ESD is funded by Leicestershire District Health Authority, and $\mathrm{CMCC}$ is funded by the Trent Institute for Health Services Research.

\section{CONTRIBUTIONS}

ESD contributed to the conception, design, execution, analysis, interpretation, and paper writing. BNM contributed to the design, analysis, interpretation, and editing of the paper. CMcC contributed to the analysis, interpretation, and paper editing. DJF contributed to the conception, design, interpretation, and paper writing.

\section{Authors' affiliations}

E S Draper, B N Manktelow, D J Field, Department of Health Sciences, University of Leicester, Leicester, UK

C McCabe, Trent Institute for Health Services Research, Sheffield Health Economics Group, University of Sheffield, Sheffield, UK

\section{REFERENCES}

1 Botting B, ed. The health of our children. Decennial supplement. Office of Population Censuses and Surveys Series DS NO. 11. London: HMSO, 1995

2 Macfarlane A, Mugford M, Henderson J, et al. Birth counts: statistics of pregnancy and childbirth, 2nd ed. London: The Stationery Office, 2001

3 British Association of Perinatal Medicine. Standards for hospitals providing neonatal intensive and high dependency care and categories of babies requiring neonatal care. 2nd ed. London: British Association of Perinatal Medicine, 2001.

4 Department of Health. Report of the Neonatal Intensive Care Services Review Group. London: Department of Health, 2003.

5 Tucker J, Tarnow-Mordi W, Gould C, et al. UK neonatal intensive care services in 1996. Arch Dis Child Fetal Neonatal Ed 1999;80:F233-4.

6 Maternal and Child Health Consortium. Confidential Enquiry into Stillbirths and Deaths in Infancy (CESDI). Project 27/28: an enquiry into the quality of care and its effect on the survival of babies born at 27-28 weeks. London: The Stationery Office, 2003.

7 UK Neonatal Staffing Study Group. Patient volume, staffing and workload in relation to risk-adjusted outcomes in a random, stratified sample of all UK neonatal intensive care units: a prospective evaluation. Lancet 2001;359:99-107.

8 Field D, Draper ES Survival and place of delivery following preterm birth: 1994-96. Arch Dis Child Fetal Neonatal Ed 1999:80:F111-15. 